\title{
Correction to: Official 3D Spatial Base Data in Germany
}

\section{Ulrich Gruber ${ }^{1}$}

Published online: 16 April 2020

(c) Deutsche Gesellschaft für Photogrammetrie, Fernerkundung und Geoinformation (DGPF) e.V. 2020

\section{Correction to: PFG \\ https://doi.org/10.1007/s41064-020-00097-x}

The publication of this article unfortunately contained a mistake. A second author was erroneosusly added and has been removed. The corrected list of authors is given above.

1 Fachdienst Kataster und Geoinformation, Kurt-Schumacher-Allee 1, 45657 Recklinghausen, Germany 